\title{
JUÓ BANANÉRE, O RATÉ DO MODERNISMO PAULISTA?
}

\author{
Elias Thomé Saliba \\ Depto. de História - USP
}

RESUMO: Este artigo busca refazer parte da trajetória do cronista paulistano Juó Bananére a partir do ano de 1915, que marca o início da campanha nacionalista de Olavo Bilac. Com aparições efêmeras e circunstanciais na imprensa, o humor de Juó Bananére, com seu anarquismo lingüístico, será sempre inoportuno face ao quadro predominante de nacionalismo mais programático, característico dos anos que antecedem o modernismo de 1922. No início dos anos trinta, com colaborações em A Manha, de Aparício Aporelly e com a fundação do seu próprio pasquim, o Diário d'o Abax'o Piques, o cronista se multiplica em inúmeros outros calungas falantes, reafirmando o colorido rebarbativo - e impertinente - da cultura paulista da Belle Époque.

ABSTRACT: This article aims to reconstruct part of the trajectory of the chronicler Juó Bananére, from São Paulo, since 1915, year which marked the beginning of Olavo Bilac's nationalist campaign. With ephemeral and circunstantial appearances in the press, Juó Bananére's good temper, with its linguistic anarquism, was always opportune in the context of the programatic nationalism which was characteristic of the years that preceded the modernism of 1922. In the beginning of the 1930's, with contributions to Aparício Aporelli's A Manha, and with the foundation of his own pasquim, Diário d'o Abax'o Piques, the chronicler contributed to reasserting the provoking - and impertinent - side of the culture of São Paulo's Belle Époque.

PALAVRAS-CHAVE: Humor, Crítica Cultural, Modernismo, Nacionalismo, Literatura.

KEYWORDS: Humour, cultural criticism, nationalism, modernism, literature.

Juó Bananére, pseudônimo do mais ou menos famoso Alexandre Ribeiro Marcondes Machado, iniciou sua carreira em 1909, embora tenha começado a escrever com maior regularidade em $O$ Pirralho, a partir de 1912. Nesta época, Marcondes Machado era estudante da Escola Politécnica, situada no Bom
Retiro, lugar bucólico, visto pelos cronistas daqueles tempos idos e vividos, como o "mais italiano" dos bairros paulistanos na primeira década do século. Bananére escrevia numa língua própria, anárquica, em paulistaliano, segundo Monteiro Lobato, em macarrônico, segundo Otto Maria Carpeaux ou em 
ítalo-paulista, segundo a célebre caracterização feita por António de Alcântara Machado: "as deformações da sintaxe e da prosódia, aqui italianização da língua nacional, ali nacionalização da italiana", resultando "numa saborosa salada ítalo-paulista". Em estudo anterior, apoiado numa leitura mais ampla de outros cronistas coetâneos a Juó Bananére e à Belle Époque Paulista, sugerimos que a linguagem de Bananére, como possível filtragem da oralidade da época, seria muito mais italo-caipira (SALIBA, a, 1992, p.54 ).

Afora algumas indicações esparsas, é pouco conhecida a trajetória do cronista Juó Bananére após o fim de suas atividades em $O$ Pirralho no ano de 1915. Antes desse ano, Bananére havia interrompido sua colaboração por alguns meses, segundo o próprio Marcondes Machado, por "incompatibilidade" com o diretor do pasquim o "Sr. Babi (Benedito) de Andrade e sua péssima orientação"; após esta interrupção, Bananére retoma sua contribuição em outubro de 1914, quando o jornal volta a ser dirigido e animado por Oswald de Andrade. Mas, após 1915, e até a sua morte em 1933, pouco se sabe a respeito de sua trajetória e da sua produção. O objetivo deste artigo é refazer parte desta trajetória, e sobretudo apresentar alguns dados a respeito de suas relações com alguns escritores participantes do modernismo paulista de 1922.

Juó Bananére escreveu em O Pirralho, até outubro do ano de 1915, quando, então, deixou de fazer parte da redação do jornal. A primeira menção a este episódio da saída do cronista de $O$ Pirralho, foi feita por Brito Broca em 1958, em artigo no qual o notável crítico terminava perguntando, a si próprio, quais seriam os reais motivos da demissão do cronista macarrônico daquela prestigiosa publicação (BROCA, 1991, p.327a). Bananére escreveu em O Pirralho portanto, até outubro de 1915, quando Olavo Bilac esteve em São Paulo para lançar sua campanha nacionalista, a partir de sua famosa pregação aos estudantes da Faculdade de Direito.
O ano de 1915 é crucial para a campanha nacionalista, iniciada por Olavo Bilac justamente a partir de São Paulo. A Belle Époque paulista foi permeada por várias visitas de escritores cariocas à capital do café para proferir conferências ou recitais de poesia. As palestras eram organizadas, em geral, sob o patrocínio da Sociedade de Cultura Artística, animada por Luis Silveira, Pinheiro Júnior e Nuto Sant'Ana mas, a recepção aos escritores, como de praxe, era realizada na Faculdade de Direito. Foi assim, no ano anterior, quando esteve em São Paulo, o poeta Emílio de Menezes. $\mathrm{O}$ autor de Os deuses em ceroulas, chegara mesmo a abdicar da sátira para escrever um poema em homenagem a São Paulo e a Washington Luis, intitulado Non Ducor, duco, que, sem nenhuma sutileza, assim terminava:

Aí estás agasalhando o paulista agasalho Que é o berço da beleza e a fonte de energia, Fonte da intrepidez e berço do trabalho. (MENEZES, 1980, p.52)

Lembre-se que, ainda no início de 1915, é o próprio João do Rio que vem a São Paulo, hospedandose na "Rôtisserie Sporstman", então o melhor hotel da cidade, sendo depois recebido entusiasticamente também na Faculdade de Direito, ali proferindo o seu discurso “Oração à Mocidade"- peça laudatória a São Paulo e aos jovens escritores reunidos em torno do prefeito Washington Luis. Mário Guastini, nas suas memórias, chega mesmo a afirmar que João do Rio precedera Bilac na campanha cívica que este desencadearia em São Paulo, alguns meses depois:

Bilac, ao iniciar suas conferências e discursos à mocidade, - escrevia Guastini - encontrara o terreno excelentemente preparado. Antes dele, Paulo Barreto conversara com esta mesma mocidade que entusiasticamente o aclamara. Da Faculdade de Direito de São Paulo partiu o primeiro grito de alerta. Esse grito foi de Paulo Barreto (GUASTINI, 1939, p.142). 
Assim, Bilac já encontrara o terreno preparado por João do Rio, e este só não granjeara a fama de iniciador da campanha nacionalista, talvez pelo furor dos seus inimigos, que o acusavam, segundo o mesmo Guastini, de "teúdo e manteúdo dos cofres públicos paulistas". Tais acusações apenas aguçariam a mágoa pessoal de João do Rio em relação aos seus detratores e, mesmo depois, em relação a São Paulo. O mesmo João do Rio, em depoimento reservado confessaria:

"Esta gente de São Paulo, meu caro, alucinada pela glória de suas bandeiras perdeu o senso comum: entende que jornais e revistas devem encher páginas de aplausos aos seus triunfos, de graça, sem o dispêndio até de um comezinho muito obrigado... Está, positivamente, mal habituada e quem assim a habituou foi eu..." (João do Rio apud GUASTINI, 1939, p.127)

Lembre-se ainda que no mesmo ano de 1915 , Amadeu Amaral esteve no Rio de Janeiro, onde recebeu muitas homenagens dos escritores cariocas, uma espécie de preparação à sua eleição para a Academia, que ocorreria apenas em 1919. Assim, toda uma série de mensagens precedem a visita de Olavo Bilac, "príncipe dos poetas" a São Paulo. Amadeu Amaral, por exemplo, diagnosticou, alguns dias antes da visita, que São Paulo era escolhida (por Bilac) por ser uma "cidade nacional, centro de convergência, foco de irradiação de energias brasileiras, de idéias brasileiras, de inspirações brasileiras". Mas se examinarmos a correspondência íntima de Bilac, veremos que a imagem que ele tinha da cidade era completamente outra e, em qualquer caso, muito próxima até daquela "impossibilidade do retrato", vivenciada pelos obscuros cronistas macarrônicos da belle époque paulista (SALIBA, 1997b). Eis um trecho, dos mais suaves, de uma das cartas de Olavo Bilac, é certo que de tempos passados, a um dos seus amigos:

"São Paulo é uma bexiga. Isto não vale dois caracóis!(...) Receberá qualquer dia notícia de minha morte. Não posso viver numa terra onde só há frio, garoa, lama, republicanos, separatistas, camelôs e tupinambás.(...) Que estúpida cidade é São Paulo! Que gente pérfida, que clima impossível!" (BROCA, 1993b, p.58)

Mas, Bilac era então admirado não apenas por Amadeu Amaral, Júlio de Mesquita Filho e outros que, é claro, desconheciam sua correspondência mas, por toda a nova intelligentsia paulista, incluindo os jovens Oswald de Andrade e Mário de Andrade.

Contra a maré de elogios e saudações públicas ao "príncipe dos poetas brasileiros", Juó Bananére escreveu uma impertinente paródia da presença de Olavo Bilac em São Paulo e, sobretudo, da famosa oração que o poeta pronunciou aos estudantes da Faculdade de Direito. Esta paródia foi publicada, um dia depois da festiva aparição de Bilac na Faculdade de Direito, na coluna de Bananére, em $O$ Pirralho.

Bananére começa com uma notícia triunfal:

"A vesta do Bilacco - Quartaferra teve a nunciada visita du Bilacco, principe dus poeta brasileiro, o Dante nazionalo! Uh! Mamma mia, che sucesso! O saló stava xíinho di gente pindurado. Gada lustro apparicia un gaxo de banana di gente. Bilacco disse moltos suneto gotuba"1.

O problema é que a paródia envereda depois por lances mais delicados, por exemplo, quando o próprio Bananére se compara a Bilac:

Nom é só o Bilacco que é uleomo de lettera -(ío) també scrivo verso, ió també scrivo livro di poesies chi o Xiquigno vai inditá, i chi undia va vê si nom é migliore dus livros du Bilacco..

Em seguida, o próprio Bananére aparece como convidado para uma "circunferenza na Gademia di

1 "cotuba" ou "coruscuba": coisa que nos agrada plenamente, fazia parte do vocabulário caipira, derivou depois para "batuta"(Cf. AMADEU AMARAL,1976, p.117). 
Commerco du Braiz"; seu discurso, inteirinho em macarrônico, é uma paródia absolutamente anárquica da fala nacionalista de Bilac:

Signori! Io stó intirigno impegnorato con ista magnifica rocepicó chi vuceio acaba di afazê inzima di mim. É moltas onra p'un pobri marqueiz! (tutto munnno grita: nó apuiado!) Io ê di si ricordá internamente, i con molta ingratidó distu die di oggi! I aóra mi permitano che io parli un pocco da golonia italiana in Zan Baolo, istu pidaçó du goraçó da Intalia, atirado porca sorte inzima distas praga merigana. É una golonia ingolossale! Maise di mezzo milió di italiano stó ajugado aqui, du Braiz, ó Buó Rittiro, i du Billezigno ó Bizigue! I chi faiz istu mundo di intaliano chi non toma gonta du Cumerçu, das Fabrica, da pullitica, du guvernimo - i non botta u Duche dus Abruzzo come prisidenti du Stá nu lugáro du Rodrigo Arveros?

Finalmente, Bananére conclui sua arenga anárquica, parodiando a célebre retórica de Bilac. (Lembre-se, aqui, dos famosos reptos do discurso de Bilac, por exemplo, quando dizia: "O que se tem feito, o que se está fazendo, para a definitiva constituição da nacionalidade?"). Eis Bananére:

I quali é consequenza diste relaxamento? É qui os intaliano aqui non manda nada quano puteva inveiz aguverná ista porcheria! Quale é a consequenza da bidicaçó da nostra forza i du nostro nacionalismo? É chi nasce una crianza, a máia é intaliana, o páio é intaliano e illo nasce é un gara di braziliano! Istu no podi ingontinuá, no! A voiz chi sono giovani i forte cumpette afazê a reaccó, cumbattê, vencê e dinuminá istu tudo! Tegno dito" - Rompi una brutta sarva di parma. Mi begiário, mi giugáro flor e mi liváro incarregado até o bondi inlétrico" ( $O$ Pirralho, 1915, p.9).

Mas, na realidade não houve nem beijos nem abraços triunfais, pois a cidade e sua jovem elite intelectual, parece, não estavam para brincadeiras. Os estudantes da Faculdade de Direito, no dia seguinte dirigiram-se afoitos, em magotes, para uma manifestação em frente a redação d' $O$ Pirralho - que então se localizava na rua XV de novembro, exigindo a demissão do jornalista e ameaçando empastelar o jornal. Bananére é então demitido, perdendo o seu lugar de "barbieri e giurnaliste" na sua famosa coluna "Diário do Abaixo Piques" (O Estado de São Paulo, 1915, p.7). Parecia claro que, à parte as desavenças pessoais que ajudavam a fermentar o conflito, o anarquismo lingüístico de Juó Bananére não se enquadrava facilmente em fórmulas e manifestos, que pediam um mínimo de clareza, renunciando a qualquer tipo de ambigüidade.O episódio é muito revelador dos compromissos que a jovem intelligentsia de São Paulo tinha com aquele nacionalismo algo difuso mas, que se nutria de uma única certeza: sua raiz paulista, ávida por construir e reforçar uma hegemonia e, se possível, estendê-la ao campo das letras e da cultura.

Após a saída de $O$ Pirralho, o cronista macarrônico chegou a escrever, a partir de 1916, muito esporadicamente nas revistas semanais $O$ Queixoso e $A$ Vespa. Na primeira, Marcondes Machado comparece com uma coluna intitulada "Sempr'avanti! - e na segunda revista, com a sua coluna "Cartas d'Abax'o Piques." Mas será em "O Queixoso", no final do ano de 1916, que Bananére irá detonar seu segundo desentendimento com o então jovem estreante nas letras, Oswald de Andrade.

Mon Coeur Balance e Leur âme marcaram o início da carreira de Oswald de Andrade e Guilherme de Almeida em 1916. A primeira era uma comédia em 4 atos e a segunda um drama em 3 atos e quatro quadros, ambas escritas em francês, em parceria com Guilherme de Almeida. Seus autores tiveram o cuidado de colocar na capa a indicação: "Théâtre Brésilien" e, curiosamente, reservaram para si próprios os "direitos de tradução". Com um chá oferecido aos autores, a peça Leur âme teve leitura concorrida no Consulado de Portugal, por iniciativa de Ricardo Severo. Emílio de Menezes, com a concordância de Alberto de Oliveira e João do Rio, chegou a sugerir a apresentação da peça na Escola Dramática do Rio de Janeiro. Um ato da peça Leur Âme chegou a ser representado 
no Teatro Municipal, pela atriz Suzanne Desprès, que compunha a conpanhia teatral que Lugné-Poe improvisara para percorrer a América na época da guerra; Mon Coeur Balance foi lida por Poe e Marthe Regnier durante o intervalo de uma comédia que a mesma companhia apresentava no teatro municipal. (GUASTINI, 1939, p.144) Como era de se esperar, Guilherme d'Almeida e Oswald d'Andrade, - assim eles se assinavam então - dedicaram esta estréia a Washington Luís: Monsieur le Docteur Washington Luís Pereira de Sousa, Préfet de la Ville de São Paulo. E, completando a dedicatória, com palavras que lembravam a conjuntura de guerra, mas também o programa nacionalista, lançavam encômios ao patrocinador de futuros eventos culturais paulistas:

Nous avons voulu faire de celle première pièce notre écu de combat. Qu'on lise, en le blasonnant, votre nom - pièce honorable que nous y posons en abîme. (ANDRADE, 1991, p.20)

A voz discordante foi Juó Bananére que, sem nunca ter escrito em francês (e muito raramente em português, diga-se, a bem da verdade), numa coluna do obscuro jornal $O$ Queixoso, atacou a obra, ressaltando o cabotinismo da peça Mon Coeur Balance. O texto de Bananére é, juntamente com a explicação anterior da sua "incompatibilidade" com Baby de Andrade em 1914, talvez um dos únicos que o autor de La Divina Increnca tenha escrito na comportada língua portuguesa e não na sua costumeira (e intrinsecamente anárquica) língua macarrônica.

Bananére começa por ironizar o fato da peça ter sido escrita em francês, dizendo ter quase certeza que "se os autores tivessem escrito a sua peça em português, teriam passado inteiramente despercebidos do público e da imprensa, e somente alguns amigos teriam sabido dos seus esforços e da sua produção". Contudo, depois de lembrar que a "brio nacional anda de rojo pelas sarjetas", já que a "etiqueta estrangeira vale 50 por cento mais que a nacional", Bananére exclama, num desabafo:

Oh! Que bom seria se Deus, num largo gesto de misericórdia e piedade, desabasse contra nós um cataclysma que, fundindo o Brasil, de norte a sul, absorvesse estes vinte milhões de vencidos, que no meio de uma natureza exuberante e pródiga, rastejam e se rojam pela lama do cabotinismo, ou então que nos mandasse, como ha poucos dias me dizia um amigo, um novo Pedro Alvares Cabral, para recomeçarmos a vida. (O Queixoso, 1916, p.2).

Oswald de Andrade devolveu a coisa, num desaforado bilhete datado do mesmo dia 13:

"Bananére, antes de tudo uma banana por saudação natural. De certo na notícia preciosamente escrita e colossalmente raciocinada que deu O Queixoso sobre Mon Coeur Balance, esqueceste este tópico: "Enfim, dos males o menor - antes ser cabotino do que raté”. (BOAVENTURA, 1995, p. 43).

Cabotino ou não, o certo é que a pecha de "raté" será uma espécie de vaticínio da trajetória posterior de Alexandre Marcondes Machado. A áspera crítica de Juó Bananére, além da óbvia motivação pessoal pelos episódios anteriores, pode ser pensada também por uma outra perspectiva. Uma análise superficial da obra paródica de Bananére mostra-nos que o seu quadro de referência teatral, já nesta época, era muito menos o teatro mais culto ou dramático do que aquilo que poderíamos chamar de burletas, peças brejeiras ou teatro de revista. Não é por coincidência que muitos dos poemas paródicos de Bananére se inspiravam nestas revistas cujos títulos eram $O$ Gabiru, de 1914; O men boi morreu, de 1916 ou O caradura, de 1918 (PAIVA, 1991, passim.; RUIZ, 1988, pp.108115).

Em 1917, Bananére escreve, em parceria com Moacyr Piza, o Calabaro, libro di saniamento suciali e, nos anos seguintes, a suas peças teatrais, cujos textos hoje estão perdidos. Bananére volta a escrever em 
O Pirralho, por mais três meses, entre março e junho de 1917, mas quando este jornal já não era mais dirigido por Oswald de Andrade. Mas, pelo menos em jornal, Bananére só voltará a escrever, quase sete anos depois, no ano de 1924, numa coluna, de periodicidade muito irregular, em $O$ Estado de São Paulo, intitulada " Grisea Pullitica". Eis então o "barbieri e giurnaliste", retornando do ostracismo de quase sete anos:

"Chi fui che dissi che io mori?! una ova che io muri!... Io apena si aritirê c'oa vida privada pur causa che fiquê molto disgustoso c'oa inleçó du Artubernardi p'ra Prisidentimo da a Ripubliga inveiz du Piedadó ${ }^{2}$ che era o minho gandidato. Io nom muri, i p'ra pruvá chi nom muri i chi sô bananera chi inda dá caxo, di oggi té u die 17 io vô dá settes caxo di banana..."

E, a partir daí, os "cachos" da bananeira foram aparecendo sucessivamente, nas páginas de $O$ Estado de São Paulo. A aparição do cronista é quase uma ressurreição. Tanto, que ele próprio parece julgar sua ressurreição efêmera ou até, inverossímil : para que ninguém duvidasse da autoria ele providenciava, junto com a sua assinatura no final do artigo, o reconhecimento da firma:

Juó Bananére - Poéte, barbiere i giurnaliste, muradore c'oa rua Oxinto Luigi n.OB. Arrigonheço a firma sopra San Baolo, 10 Feverero,1924 - C'oas tistimonia da virdadi, Pietro Gaporale, tabellió provisório di Macaé. (O Estado, 1924 )

O alvo da sátira, como se via, era nada mais nada menos que Washington Luís. Porque quase todas estas aparições na imprensa de Juó Bananére, rápidas e circunstanciais, podem ser consideradas impertinentes. Ou talvez, pelo contrário, elas foram circunstanciais e efêmeras devido à sua impertinência. Em

\footnotetext{
${ }^{2}$ Refere-se ao Coronel José Piedade.
}

1924, por exemplo, num dos seus "caxos”, Juó Bananére inventa uma entrevista ("una circunferenza") com Washington Luís, que ele chama de O "Mussolino di Macaé". Ei-la:

“-Bondie sô Mussolino!

-Bondie Bananére! O che manda?

-Io sô dottore!? Io nom mando nada! Che manda aqui nista gapitania é u signore!

-É modéstia sô Bananére!

-Intó io sô besta?! Intó io non to veno?! U signore quizi sê segretario da polizia, e fui! Quisi sê guvernatore da cittá, e fui! Quizi sê governatore du Stá di San Baolo, i fui! Quizi sê Storiadori, i fui!'Aóra u signore stá quireno sê prisidentimo da a Republiga, i a di sê! I si o signore quizé sê Papa tambê a di sê, perchê San Pietro non era to importanti come $u$ signore fui!! Chi ti vê oggi i che ti viu! Chigné chi á di dize chyi vucê giá fui barítono abarato in Batatalo, vucê chi oggi ganta di gallo пи Brasile intero, i ninguê ganta maise artu chi chi vucêe?!" (O Estado, 1924 )

À parte o inconveniente maior de chamar Washington Luís, sem muita sutileza, de um autêntico “antipapa” temos aí uma pérola da prosódia, mostrando o quanto Bananére havia aperfeiçoado, nos sete anos de ausência nos jornais, o seu macarrônico: ressalte-se que, nesta tresloucada entrevista, ele transforma "cantor barato em Batatais" em "barítono abarato in Batatalo", frase cheia de musicalidade, embora daquele tipo também esquisito, meio atonal. Lembrese que Washington Luis havia não apenas auxiliado financeiramente o pasquim $O$ Pirralho, pelo menos nos seus primeiros tempos, como também incentivou um difuso mecenato em relação à Semana de 22 e outros eventos culturais paulistas na mesma década.

Depois disto, o arquiteto Juó Bananére voltaria apenas em agosto de 1927, em aparições dispersas, mas sempre desconcertantes, no Diário Nacional colaboração que se manterá, de forma muito esporádica, até 1928 (Diário Nacional, 1927) Em fevereiro de 1931, a convite de Aparicio Aporelly - o futuro Barão de Itararé - Bananére também irá mandar seus escritos, muito circunstancialmente, para o famoso periódico humorístico do Rio de Janeiro, A Manha, 
colaboração que o barbieri i giurnaliste irá manter até sua morte em agosto de 1933. (A Manha, 1931)

Em 1931, Bananére grava alguns dos seus poemas e crônicas em discos da Columbia, entre eles, uma estapafúrdia narrativa do descobrimento do Brasil na qual, "Pietro Alvares Caporal", trazendo da Europa um carregamento de tagliarini é perseguido por baleias até chegar na cidade de Santos, "prá grandi incontentamento da populaçó locali”. A voz de Marcondes Machado nestas gravações revela extrema habilidade artística, ao captar todos os trejeitos da fala ítalo-caipira, intraduzíveis na linguagem escrita. (BANANÉRE, 1931, disco)

A última aparição pública de Juó Bananére será num jornalzinho no qual ele, pelo menos, não tinha que prestar contas a ninguém. Assim, em 3 de maio de 1933, Juó Bananére aparece com o seu Diário do Abax'o Piques, pasquim que ele escreve sozinho, nos fundos de sua casa na Rua Alagoas. O Diário continha o seguinte expediente: Diário semanale di grande impurtanza, pruprietá di una sucietá anônima cumpretamenti disconhicida. Órgano ingapotado do fascimo intaliano i du "Oglio di Mosco in Zan Paolo. Logo no primeiro número, Bananére homenageia o poder político com um dos seus tradicionais:

Sonetto Ippico:

Treis di Maggio! Dia di libertá!

$O$ sole manheceu apindurado nas artura.

Una atentativa mais si vai tenta

P'ra liquidá di una veze c'oa Dentadura.

Da bocca das orna di voto nas mó,

O Zépovo da Naco braziliéra.

Vai dizê p'ru pissoal da inrivoluçó

Chi non quere maise sabe di bringadêra.

Inquanto era tutto novitá:

Banqueto daqui, disgorso di lá,

Stava tutto molto bó!

Ma bringá di Dentadura a vita intêra,

C'um freio na bocca $i$ un rabixo na trazêra,

Isso nó!

(Diario d'O Abaxo'Piques, 1933)
Na edição de 3 de maio de 1933, Bananére chega a lançar seu próprio partido e num "artigo prugrama", arrematava:

“...o nostro prugramma sintetico stá scritto no nostro gabeçario traveis da celebre eufrazia du difuntimo poeta Dantis: 'Lasciati ogni speranza, ó voi ch'entrate!',o che in vernacolo do tempo do Gamonhes quere dizê: - Entrô aqui, é o páu da guaiabêra!(O Pirralho, 1933, p.1)

Como se vê, a sutileza não era o ponto forte do poeta Juó Bananére mas, seu pasquim, certamente, deveria ter muitos leitores. Talvez porque, como sugeriu na mesma época António de Alcântara Machado, com Bananére, "o ridículo dos homens e das coisas ganhava um colorido gritante que o fazia percebido pelos olhos mais ingênuos" (MACHADO, 1933, p.47). O Diário d'O Abax'o Piques, publicado por alguns meses em 1933 foi, portanto, a despedida de Juó Bananére. Neste curto espaço de tempo, vemos Alexandre Marcondes Machado dividir-se nos mais diversos pseudônimos, cada um com uma língua própria, numa multiplicação quase infinita dos dialetos bananerianos.

Por exemplo, Salim Gamons, que escrevia numa mistura das línguas árabe, judaica e armênia - no seu "Soneta clássicas", evidente parodia de Camões onde ele diz:

"Sete annos, Jacu servia Maquel,

Sem canhaá nada, balavra Teus!

Só pra cazá con a tona Raquel

O mais bonita filha te xudeus."

O soneto termina, é claro, com um rompante nada romântico, onde o vate, com medo das dívidas e dos juros, deseja, literalmente, despachar a Musa para qualquer um que a aceite:

"Eu trabalho te crassa mais teis anno!

Eu até mata genti pricizáno... balavra teus,

Mas, fica com Loxa e com Raquel." (Diario d'Abaxo'Piques, 1933 ) 
Ou, então, a coluna escrita quase sempre na pagina 3, O Taka Chumbo Shimbun, cujo diretor era o sr. TEBATO NAKARA e que, já no número 4 , anuncia:

“...uma impotante konfelencia sekereta ki haveu onti ni skiritório di nossa zona, ninguém pissoa sabeu. Tomando parti néra a sancerér aremão Adolpho Hitri( ki shego skondido ni Zeperin) Zuon Bananéri, diletô di este fôria, Dotô Tebato Nakara, diletô zapanezi. Elli farou diwagarinho que pixiza fazi marsha di farambô kum ranterna zapanezi ni wenida paurista, tokando Bawa zenti bazirêra $i$ Zaponezi di pátria firio.!" (Idem)

Ou as paródias escritas sob o cognome de Pacheco D'Eca, como esta, aparecida em 20 de julho de 1933:

"Xou pertuguês, ha quatroçantos anos:

Minh'alma é a mesma, qu'enfunaba as belas

Qu'arrastaram a glória as carabelas

Dus heróicos merujos luzitanos. (...)

u mare aos luzos tudo deu: Primairo,

Deu-nos de graça um continante intairo,

Deu-nos ilhas, d'spois, a dar c'un pau.

Hoje, qu'as cousas stão dif'rantes,

Inquepaz de nos dar' mais cuntinantes

Faz u qu'a pode, e dá-nos... Vacalhau.” (Idem,p.2 )

Salim Gamons, Pacheco d'Eca, Tebato Nakara eram os múltiplos heterônimos utilizados por Juó Bananére para falar de uma sociedade, como sempre marcada, pela heterogeneidade, pelo deslocamento e pela desagregação. Também neste caso, o humorismo de Bananére também era impertinente: falava-nos de um passado muito próximo, cheio de rebarbas, ressentimentos e, até, renitentes preconceitos sociais num momento em que, simbolicamente, tudo convergia para um nacionalismo fortemente disseminado. Não se tratava mais de confrontar o nacionalismo com o cosmopolitismo, como no período inicial da República, mas de entabular e sinalizar uma nova antítese entre um matiz de nacionalismo assimilacionista, contra outro, mais intransigente. Forjar novos laços simbólicos neste novo quadro, implicava em apagar as marcas de um passado bastante recente, nunca mencionando, ou tentando assimilar aquela chusma de imigrantes que tumultuara a cena social brasileira na Primeira República (SEVCENKO,1992, passim).

Bananére permaneceu escrevendo e aperfeiçoando o seu dialeto macarrônico, sem nunca interessar-se por escrever numa língua culta. Isto, juntamente com a impertinência que era intrínseca à sua criação, o afastou definitivamente da literatura e da vida literária. Até o final, Bananére insistia em juntar suas duas atividades paralelas imaginárias, tão nobres quanto dignas: barbieri i giurnaliste, embora ele reconhecesse que, nos anos trinta, nem o jornalismo e nem a barbearia, garantiam a sobrevivência. Ele escreve, em 1933: "A vita stá dificille pr'a burro! Us frigueiz nom vó maise nu saló afaze a barba. Tuttos gompra una navaglia Gigollete per trezentó i faiz a barba in caza a settimana intirinha. A literattura non dá maise nada! Anticamenti io afaceva unos versinho p'ros namurado dá p'ras anamuradas i acanhava unos caraminguado. Oggi inveiz illos non quere sabe maise di verso - pega a piquena, amunta na baratina e sái, comme un empiastro..". (Diario d'O Abaxo'Piques, 1933). Aqui, curiosamente, o barbeiro, pela introdução da lâmina gilette, tanto quanto o poeta, pela introdução do automóvel rápido, que quebra com a duração necessária aos hábitos do leitor - transmutamse em ratés da modernidade - daquela modernidade canhestra e híbrida construída pela história de São Paulo.

Mas não era apenas a situação do Barbeiro e do jornalista que estavam críticas. Elas apenas coincidiam com a situação pré-falimentar do país e do Estado. Eis portanto, o nosso cronista de volta à realidade bem cotidiana, com seu diagnóstico, sempre muito pouco sutil:

\footnotetext{
“ $O$ gambio, c'oa inrivoluçó

Tive tamagna incomoçól

Chi tive una zincopis

I murreu du goraçó

$O$ goitadigno do gaffé

tambê tive un susto danado
} 
I fico alegiado

Dos Quatro pé."

E, para ninguém reclamar do não entendimento do seu diagnóstico, completava:

"Con Zan Baolo quibrado

Co Gaffé alegiado

Co Gambio inscangagliado

Co tizôro arribentado.

I co Gioareiz na Gricortura,

Stamos na dipindura

Nóis e a Dentadura. ....."

(Diario d'O Abaxo'Piques, 20.04.1933)

Porque Bananére foi alijado do circuito da cultura dominante paulista? Esperamos ter apresentado ao leitor alguns elementos de resposta.

Multiplicação de nomes e de personagens, esvaziamento da sua própria identidade, de qual cidade Bananére tentava falar? Bananére, ou, o pouco que restou dele depois da sarabanda modernista, parece ter ficado também preso à tradição de uma cidade cujas referencias urbanas não mais existiam. $O$ Piques, onde ele tinha o seu salão de barbeiro, o Bom Retiro, das costureirinhas chiques e onde ele morava com Juóquina e seu filho imaginário, o Beppino; o Brás, com suas fábricas e os bondes "caraduras" da Ligth. A referência ao Piques é constante em Bananére: ele continua falando no Piques em 1933, época no qual o Piques já não mais existia. Mas, parte das pessoas que o liam sabia onde ficava o Piques, sabia também que, neste mesmo lugar, no início do século passado eram realizados concorridos leilões de escravos. Estas pessoas não apenas sabiam onde ficava o Piques, que se confundia com a própria história de São Paulo, mas também se identificavam com esta referência urbana da cidade.

Bananére, nas raras vezes em que conseguiu aparecer, insistiu em preservar a anarquia do humor, a desordem do seu lirismo e a ambigüidade intrínseca do seu discurso. Por mais sérios que fossem os assuntos, a própria língua macarrônica fazia com que a seriedade derrapasse, quebrando todo e qualquer determinismo. Podemos surpreender Bananére num desses momentos, quando em 1933, falando sobre as eleições para a Assembléia Constituinte, começa com um discurso de sincero sentimento de nacionalismo paulista, que vai deslizando, deslizando, até concluir com a peremptória frase: "São Paulo é incivilizattto pr'a burro" Eis o texto, por inteiro:

"Qüera o non qüera, pissoalo, vuceis tê de arrigonhecê chi Zan Baolo é o lidero sudamerigano. É o maiore centro industriali da Ameriga do o Suli, na pinió dos bondi da Laita. É o maiore centro improduttore di caffé; é o maiore centro isportadore di fruittas, garne di bóio e garne di vacca, é a vacca di latte chi amammente suzinho os goffre da unió; i é o centro mais incivilizato p'ra burro das terra adisgoberta da o Pietro Caporale”. (Diario d'O Abax'o Piques, 15.06.1933).

O recurso da paródia bananeriana neste discurso é semelhante ao Bathos, uma figura de retórica que significa uma descida cômica de um plano elevado ao lugar- comum, ao prosaico. Mas o que é característico de Bananére, contudo, é que esta figura ocorre pela repetição de lugares-comuns, que, por isto mesmo, estão sempre deslocados do seu significado original. É o que ocorre quanto Bananére, desta feita em junho de 1933, defendendo a participação das mulheres na Constituinte, faz uma "circunferenza" com a "Dottora Garlota Kiroiz”, que ele designa como "Indisputada a Constituinte". Indisputada, em macarrônico é "deputada” mas, é impossível também não ler indisputada, ou seja, aquela que ninguém disputa, aquela que, afinal, ninguém quer... A linguagem se desvia, sem aviso, no meio do parágrafo, das armadilhas da unidade e da identidade, e recai no desconforto, na desintonia, na fragmentação. O estudo da anarquia linguiística de Bananére ainda aguarda análises mais acuradas. Mas ele será condição para avaliar a impertinência da obra efêmera e circunstancial de Juó Bananére? 
Nunca será demais lembrar - pois o silêncio da maioria dos intérpretes a este respeito é assustador - que, ao contrário do modernismo paulista, cuja tônica acabou sendo idealista, nativista, nacionalista e militante, o humor de Bananére era desmobilizador, anárquico, lírico e anti-programático (SALIBA, 1993). Talvez, por isto, ele tenha sido - alterando um pouco a pecha lançada pelo jovem Oswald de Andrade - um autentico raté do modernismo paulista. Foi um raté talvez porque

\section{Bibliografia:}

BANANÉRE, Juó e PIZA, Moacyr. Calabaro. São Paulo, s.c.p., 1917.

BANANÉRE, Juó. Non fui ista a inrevoluçó qui io sugné. Disco Colúmbia. 22034 B, 1931. U indiscobrigmiento du Brasile. Disco Colúmbia. 22034-A, 1931

O Estado de São Paulo. São Paulo, 13.02.1924.

Diário d'O Abax'o Piques. São Paulo, 03.05.1933; $20.04 .1933 ; 15.06 .1933 ; 20.07 .1933 ; 17.08 .1933$.

Diário Nacional. São Paulo, 28.08.1927 a 06.01.1928.

O Queixoso. São Paulo, 11.01.1916.

A Manha. Rio de Janeiro, de 27.02.1931 a 19.08.1933.

AMARAL, Amadeu. $O$ dialeto caipira; gramática, vocabulário. $3^{\mathrm{a}}$ ed. São Paulo, Hucitec-Secretaria da Cultura do Estado de São Paulo, 1976.

BROCA, Brito. Naturalistas, Parnasianos e Decadistas;vida literária do Realismo ao Pré-Modernismo. Campinas, Editora da UNICAMP, 1991a.

BROCA, Brito. Teatro de Letras. Campinas, Editora da UNICAMP, 1993b.

MENESES, Emílio de. Obra Reunida. Rio de Janeiro, José Olympio; Curitiba, Secretaria da Cultura do Estado do Paraná, 1980.

PAIVA, Salvyano Cavalcanti de. Viva o Rebolado! Vida e morte do Teatro de Revista brasileiro. Rio de Janeiro, Nova Fronteira,1991. tenha mantido, até o final, seu apego à modernidade enviesada e canhestra da belle époque brasileira. Mas ficou à margem, sobretudo porque não queria nada e não pretendia ensinar nada: com suas paródias e sátiras, talvez tenha sido apenas um corte inoportuno no tempo, uma epifania da emoção, abrindo apenas uma brecha aquela pequena vereda anárquica na narrativa de uma cultura triunfante que, nós, como historiadores, nos esforçamos sempre por reencontrar.

MACHADO, António de Alcântara. "Juó Bananére". In: BARBOSA, Francisco de Assis (org.), António de Alcântara Machado: trechos escolhidos. Rio de Janeiro, Agir Editora, 1969

ANDRADE, Oswald de e ALMEIDA, Guilherme de. Mon coeur balance/Leur Âme. Rio de Janeiro, Globo, 1991.

GUASTINI, Mário. Na Caravana da Vida. Rio de Janeiro, Pongetti, 1939.

BOAVENTURA, M. Eugenia. O salão e a selva; uma biografia ilustrada de Oswald de Andrade. São Paulo, Ex-libris, Campinas, Edit. da Unicamp, 1995.

RUIZ, Roberto. Teatro de Revista no Brasil; do início à $I^{a}$ Guerra Mundial. Rio de Janeiro, MINC/INACEN, 1988.

SEVCENKO, Nicolau. Orfeu extático na Metrópole; São Paulo sociedade e cultura nos frementes anos vinte. São Paulo, Cia. das Letras, 1992.

SALIBA, Elias Thomé. "Juó Bananére e o humor ítalocaipira”, Revista de Cultura Vozes, 3, maio-junho de 1992, vol.86, pp. 53-58.

"A Macarrônea dos Dezenraizados: o humor paulista na Belle Époque", In: DIAS, Maria Odila S. (org.). São Paulo: Metrópole Dissonante. São Paulo, Editora Annablume/Secr.Cultura, 1998. (no prelo).

"Cultura Modernista em São Paulo", Estudos Históricos, $\mathrm{n}^{\circ} 11$, Janeiro-Junho, Rio de Janeiro, CPDOCFGV, 1993, pp. 128-131.

Endereço do Autor: Departamento de História • FFLCH/USP • Av. Professor Lineu Prestes, 338 • CEP 05508-900 • São Paulo - SP • Brasil • Fax(055) 011-818-3150 